\title{
Comparative Study of Dexmedetomidine and Clonidine as Adjuvant to Ropivacaine in Supra Clavicular Brachial Plexus Block
}

\author{
Chinchu Rose Steby ${ }^{1}$, Satheedevi P. ${ }^{2}$, Sunilkumar T.S. ${ }^{3}$, Sunil R. ${ }^{4}$, Reshma Rajkumar ${ }^{5}$ \\ 1, 2, 3, 4, 5 Department of Anaesthesiology, Government Medical College, Thrissur, Kerala, India.
}

\section{ABSTRACT}

\section{BACKGROUND}

Effective postoperative pain control is an important part of postoperative care which leads to shortened hospital stays, reduced hospital costs and increased patient satisfaction. Variety of adjuvants has been used along with local anaesthetics in regional blocks to increase the duration of effective analgesia. We have conducted a prospective study to compare the effect of clonidine and dexmedetomidine as additives to $30 \mathrm{ml}$ of $0.5 \%$ ropivacaine in supraclavicular brachial plexus block for upper limb orthopaedic surgeries.

\section{METHODS}

A prospective study was conducted among 50 patients belonging to ASA 1 or 2 undergoing upper limb orthopaedic surgeries under supraclavicular brachial plexus block. Patients who received $1 \mathrm{mcg} / \mathrm{kg}$ clonidine added to $30 \mathrm{ml}$ of $0.5 \%$ ropivacaine in supraclavicular brachial plexus block were taken into Group A. Patients who received $1 \mathrm{mcg} / \mathrm{kg}$ dexmedetomidine added to $30 \mathrm{ml}$ of $0.5 \%$ ropivacaine in supraclavicular brachial plexus block were taken into Group B. Sensory block - onset, duration; motor block - onset and duration; duration of analgesia were monitored and recorded. Data analysed using IBM SPSS (version 17) software. $P$ value $<0.05$ was considered as statistically significant.

\section{RESULTS}

Onset of sensory block was $9.04 \pm 1.74 \mathrm{~min}$ in clonidine group and $12.0 \pm 2.00 \mathrm{~min}$ in dexmedetomidine group which was statistically significant. Onset of motor block was $11.80 \pm 1.87 \mathrm{~min}$ in clonidine group and $15.48 \pm 2.08 \mathrm{~min}$ in dexmedetomidine group which was statistically significant. Duration of motor block was $502.8 \pm 60.9$ min in clonidine group and $566.0 \pm 59.6 \mathrm{~min}$ in dexmedetomidine group which was statistically significant. Duration of sensory block was $589.2 \pm 56.6$ min in clonidine group and $673.6 \pm 53.4 \mathrm{~min}$ in dexmedetomidine group which was statistically significant. Duration of analgesia was $665.20 \pm 52.20 \mathrm{~min}$ in clonidine group and $760.40 \pm 48.20 \mathrm{~min}$ in dexmedetomidine group which was statistically significant.

\section{CONCLUSIONS}

The addition of clonidine to $0.5 \%$ ropivacaine in supraclavicular brachial plexus block significantly reduces the onset of sensory block and motor block whereas addition of dexmedetomidine significantly prolongs the duration of sensory and motor block compared to clonidine. Addition of dexmedetomidine also prolongs the duration of analgesia compared to clonidine.

\section{KEY WORDS}

Supraclavicular Brachial Plexus Block; Ropivacaine; Clonidine; Dexmedetomidine.
Corresponding Author:

Dr. Satheedevi P.,

Additional Professor,

Department of Anaesthesiology,

Government Medical College,

Thrissur, Kerala, India.

E-mail: drsathee171@gmail.com

DOI: $10.14260 /$ jemds/2022/69

How to Cite This Article:

Steby CR, Satheedevi P, Sunilkumar TS, et al. Comparative study of dexmedetomidine and clonidine as adjuvant to ropivacaine in supra clavicular brachial plexus block. J Evolution Med Dent Sci 2022;11(02):358362, DOI: 10.14260/jemds/2022/69

Submission 19-01-2022,

Peer Review 23-01-2022,

Acceptance 03-02-2022,

Published 05-02-2022.

Copyright (C) 2022 Chinchu Rose Steby et al. This is an open access article distributed under Creative Commons Attribution License [Attribution 4.0 International (CC BY 4.0)] 


\section{BACKGROUND}

Poorly controlled postoperative pain is associated with increased morbidity, functional impairment, affects the quality of life, delayed recovery time and higher health care costs. Brachial plexus block is one of the peripheral nerve blocks which has been used for surgeries of upper limb. ${ }^{1}$ It provides both intraoperative anaesthesia as well as postoperative analgesia. ${ }^{2}$ Its advantages over general anaesthesia were effective analgesia with adequate motor blockade, awake patient, extended postoperative analgesia, early mobilization, no airway manipulation, polypharmacy was avoided and reduced incidence of postoperative nausea and vomiting. ${ }^{3}$

Many local anaesthetics has been used to produce brachial plexus block. ${ }^{4}$ Most used is bupivacaine, because of its higher potency and prolonged duration of action. One of the disadvantages is that its cardiotoxicity. Ropivacaine was developed with properties similar to bupivacaine, having lower lipid solubility and less cardiotoxicity.5,6,7

Adjuvants are used for faster onset, denser block and for prolonging the duration of peripheral nerve blockade. Alpha2-adrenergic agonists were chosen for their sedative, analgesic, antihypertensive and antiemetic properties along with decreased requirement of drugs $\mathbf{s}^{8,9,10}$ clonidine, a partial alpha 2 agonist has been shown to prolong the duration of anaesthesia and analgesia in nerve blocks.11,12,13 Dexmedetomidine, a selective alpha 2 agonist, with eight times more affinity to that of clonidine and had shown to prolong the sensory and motor duration when added as an adjuvant to local anaesthetic in nerve blocks. 14,15,16,17

There are not many studies available with regard to use of dexmedetomidine as adjuvant in supraclavicular brachial plexus block with ropivacaine and with this study I am trying to identify the cost-effective mode of analgesia with less side effects. Objectives of the study is to compare the effects of dexmedetomidine and clonidine as adjuvant with ropivacaine used for supraclavicular brachial plexus block with respect to onset time of sensory block, onset time of motor block, duration of sensory block, duration of motor block and duration of analgesia.

\section{METHODS}

This prospective study was undertaken in Government Medical College, Thrissur, from November 2018 to October 2019 after obtaining ethical committee clearance as well as informed consent from all the patients. A total of 50 patients with 25 in each group belonging to American Society of Anesthesiologists Physical Status (ASA-PS) class I and II, aged 18-60 years undergoing orthopaedic upper limb surgery under supraclavicular brachial plexus block were included. The sample size was calculated using the formulaFor $5 \%$ level of significance and $80 \%$ power $2\left(\sigma^{2} \sigma^{2}\right)(z+z)^{2}$ $\mathrm{d}^{2}$ (where $\mathrm{z}_{\sigma}=1.96, \mathrm{z}_{\beta}=0.84, \mathrm{~d}=\mu 1-\mu 2$ )

$=\frac{\left\{(1.754)^{2}+(1.68)^{2}\right\} \times 2 \times 7.84}{(9.27-11.6)^{2}}$

$=17$
That is 17 is the minimum sample size required in each group, where $\sigma 1$ and $\sigma 2$ are the standard deviations and $\mathrm{d}$ is the absolute difference between 2 means. Sample size is calculated for $5 \%$ type 1 error (P value $<0.05$ ) and $80 \%$ power of study. Values are selected from previous study by Sarita S Swami et al. published in Indian Journal of Anaesthesiology, September 13, 2017.

After getting clearance from institutional research and ethics committees, study subjects were selected based on inclusion and exclusion criteria. The study drug to each patient has been decided prior to the study by anaesthesiologist other than the researcher. The study population is divided into 2 groups with 25 patients in each group. Group A who have already received $30 \mathrm{ml} 0.5 \%$ ropivacaine $+1 \mathrm{ml}(1 \mathrm{mcg} / \mathrm{kg}$ clonidine diluted with distilled water). Group B who have received $30 \mathrm{ml} 0.5 \%$ ropivacaine + $1 \mathrm{ml}$ (1 $\mathrm{mcg} / \mathrm{kg}$ dexmedetomidine and distilled water) for supraclavicular brachial plexus block in forearm surgeries. ${ }^{18,19}$ Information regarding patient details, general physical examination, the anaesthetic drug details, intraoperative monitoring at regular intervals are obtained from the patients' anaesthesia notes which will be recorded in the corresponding case sheets.

\section{Modified Bromage Scale for Upper Limb}

0 . Normal motor function with full flexion and extension of elbow, wrist and fingers

1. Decreased motor strength with ability to move the fingers only

2. Complete motor block with inability to move the fingers.

\section{Inclusion Criteria}

Patients aged between 18 and 60 years of ASA 1 and 2

\section{Exclusion Criteria}

Patients with cardiovascular diseases, neuromuscular diseases, thyroid diseases, diabetes mellitus, hepatic or renal diseases and pregnant women.

\section{Statistical Analysis}

Quantitative analysis done using mean and standard deviation. Descriptive statistics-percentage, mean, median, $\mathrm{SD}$ will be used for describing the study variables. Unpaired $t$ test, chi square, ANOVA was used for data analysis. The "p" value of less than 0.05 is accepted as indicating statistical significance. Data analysis is carried out using M S Excel and Epi Info software (version 17).

Normally distributed data were analysed using t test and categorical data were analysed using the chi square test. Continuous data are presented as mean and standard deviation, whereas categorical data are presented as number of patients. Data was analysed using IBM SPSS statistics 20.0 software. P value less than 0.05 was considered statistically significant. 
RESULTS

The results obtained from both the groups of patients ( 1 and 2) are entered in Excel.

\begin{tabular}{|c|c|c|c|c|c|}
\hline Parameters & Group A & Group B & & & \\
\hline $\begin{array}{l}\text { Age: Mean } \\
\text { Range }\end{array}$ & $\begin{array}{l}34.2 \pm 10.1 \\
10-52 \text { yrs. }\end{array}$ & $\begin{array}{c}35.0 \pm 9.5 \\
20-49 \text { yrs. }\end{array}$ & $\mathrm{t}=0.27$ & $p=0.79$ & $\begin{array}{l}\mathrm{p}>0.05 \text { no } \\
\text { significance }\end{array}$ \\
\hline $\begin{array}{l}\text { Sex: Male } \\
\text { Female }\end{array}$ & $\begin{array}{c}21 \\
4\end{array}$ & $\begin{array}{c}17 \\
8\end{array}$ & $X^{2}=1.75$ & $p=0.19$ & $\begin{array}{l}\mathrm{p}>0.05 \text { no } \\
\text { significance }\end{array}$ \\
\hline $\begin{array}{l}\text { Height }(\mathrm{cm}) \\
\text { Mean } \pm \text { SD }\end{array}$ & $169.1 \pm 6.3$ & $166.1 \pm 8.4$ & $\mathrm{t}=1.43$ & $p=0.16$ & $\begin{array}{l}\mathrm{p}>0.05 \text { no } \\
\text { significance }\end{array}$ \\
\hline $\begin{array}{l}\text { Weight }(\mathrm{kg}) \\
\text { Mean } \pm \text { SD }\end{array}$ & $73.7 \pm 6.4$ & $71.9 \pm 6.5$ & $\mathrm{t}=0.99$ & $p=0.33$ & $\begin{array}{l}\mathrm{p}>0.05 \text { no } \\
\text { significance }\end{array}$ \\
\hline $\begin{array}{c}\text { ASA status } 1 \\
2\end{array}$ & $\begin{array}{l}15(60 \%) \\
10(40 \%)\end{array}$ & $\begin{array}{c}8(32 \%) \\
\left.17 \_68 \%\right)\end{array}$ & $X^{2}=3.94$ & $p=0.05$ & $\begin{array}{c}\mathrm{p}=0.05 \\
\text { significant. }\end{array}$ \\
\hline
\end{tabular}

\begin{tabular}{|c|c|c|c|c|}
\hline & Gr A & Gr B & \multicolumn{2}{|c|}{ Gr A v/s Gr B } \\
\hline Mean \pm SD & $9.04 \pm 1.74$ & $12.0 \pm 2.00$ & $t=5.58$ & $\mathrm{P}<0.001, \mathrm{HS}$ \\
\hline Range & $6-12$ & $9--16$ & $t=5.58$ & \\
\hline \multicolumn{5}{|c|}{ Table 2. Comparison of Onset of Sensory Block in Each Group } \\
\hline
\end{tabular}

The mean time taken for the onset of sensory block in Group A is $9.04 \pm 1.7$ min which is faster and Group B is 12.0 $\pm 2.00 \mathrm{~min}$, with $\mathrm{p}$ value $<0.001$. Hence, two groups are statistically significant.

\begin{tabular}{|c|c|c|c|c|}
\hline & Gr A & Gr B & \multicolumn{2}{|c|}{ Gr A v/s Gr B } \\
\hline $\begin{array}{c}\text { Mean } \pm S D \\
\text { Range }\end{array}$ & $\begin{array}{c}11.80 \pm 1.87 \\
9--16\end{array}$ & $\begin{array}{c}15.48 \pm 2.08 \\
12-19\end{array}$ & $t=6.57$ & $\mathrm{P}<0.001, \mathrm{HS}$ \\
\hline \multicolumn{5}{|c|}{ Table 3. Comparison of Onset of Motor Block in Each Group } \\
\hline
\end{tabular}

The mean time taken for the onset of motor block in Group A is $11.80 \pm 1.87$ min which is faster and Group B is $15.48 \pm 2.08 \mathrm{~min}$, with $\mathrm{p}$ value $<0.001$. Hence the difference is statistically significant.

\begin{tabular}{|ccccc|}
\hline & Gr A & Gr B & Gr A v/s Gr B \\
\hline Mean \pm SD & $502.8 \pm 60.9$ & $566.0 \pm 59.6$ & $t=3.71$ & $\mathrm{P}<0.001, \mathrm{HS}$ \\
Range & $360-610$ & $420-680$ & & \\
\hline \multicolumn{4}{|c|}{ Table 4. Comparison of Duration of Motor } & Block in Each Group \\
\hline t: Unpaired t test
\end{tabular}

The mean duration of motor block in Group A is $502.8 \pm$ $60.9 \mathrm{~min}$ which is shorter and Group B is $566.0 \pm 59.6 \mathrm{~min}$, which is prolonged with $\mathrm{p}$ value $<0.001$. Hence the difference is statistically significant.

\begin{tabular}{|c|c|c|c|c|}
\hline & Gr A & Gr B & \multicolumn{2}{|c|}{ Gr A v/s Gr B } \\
\hline Mean \pm SD & $589.2 \pm 56.6$ & $673.6 \pm 53.4$ & \multirow{2}{*}{$\mathrm{t}=5.42$} & \multirow{2}{*}{$\mathrm{P}<0.001, \mathrm{HS}$} \\
\hline Range & $420-680$ & $540-780$ & & \\
\hline \multicolumn{5}{|c|}{$\begin{array}{l}\text { Table 5. Comparison of Duration of Sensory Block in Each Group } \\
\text { (minutes) }\end{array}$} \\
\hline $\begin{array}{l}\text { : Unpaired t } \\
<0.001 \text {, Hig }\end{array}$ & icance & & & \\
\hline
\end{tabular}

The mean duration of sensory block in Group A is $589.2 \pm$ 56.6 min which is shorter and Group B is $673.6 \pm 53.4 \mathrm{~min}$, which is prolonged with $\mathrm{p}$ value $<0.001$. Hence the difference is statistically significant.

\begin{tabular}{|c|c|c|c|c|}
\hline & Gr A & Gr B & \multicolumn{2}{|c|}{ Gr A v/s Gr B } \\
\hline Mean \pm SD & $665.2 \pm 52.2$ & $760.4 \pm 48.2$ & \multirow{2}{*}{$t=6.44$} & \multirow{2}{*}{$\mathrm{P}<0.001, \mathrm{HS}$} \\
\hline Range & $510-750$ & $660-860$ & & \\
\hline \multicolumn{5}{|c|}{$\begin{array}{c}\text { Table 6. Comparison of Duration of Analgesia in Each Group } \\
\text { (minutes) }\end{array}$} \\
\hline $\begin{array}{l}\text { Unpaired t te } \\
<0.001 \text {, High }\end{array}$ & nificance & & & \\
\hline
\end{tabular}

The mean duration of analgesia in Group A is $665.2 \pm 52.2$ min which is shorter and Group B is $760.4 \pm 48.2 \mathrm{~min}$, which is found to be prolonged with $p$ value of $<0.001$. Hence the difference is statistically significant.

\section{DISCUSSION}

We have observed 50 patients undergoing upper limb orthopaedic surgeries under supraclavicular brachial plexus block in Government Medical College, Thrissur. The patients who have received supraclavicular brachial plexus block with $0.5 \%$ ropivacaine $30 \mathrm{ml}$ and $1 \mathrm{mcg} / \mathrm{kg}$ of clonidine were included in Group $A$ and those who have received supraclavicular brachial plexus block with $0.5 \%$ ropivacaine $30 \mathrm{ml}$ and $1 \mathrm{mcg} / \mathrm{kg}$ of dexmedetomidine were included in Group B. ${ }^{20,21,22,23}$ The study was undertaken to evaluate the efficacy of dexmedetomidine over clonidine as an adjuvant to ropivacaine for brachial plexus block ${ }^{24,25}$

Demographic data of Group A and Group B were comparable. The mean age for Group A was $34.2 \pm 10.1$ years and that of Group B was $35.0 \pm 9.5$ years. The $p$ value 0.79 was found not to be of statistical significance. The mean weight for Group A was $73.7 \pm 6.4 \mathrm{~kg}$ and that of Group B was $71.9 \pm 6.5 \mathrm{~kg}$. The $\mathrm{p}$ value calculated was 0.33 which was not statistically significant. The mean height for Group A was $169.1 \pm 6.3 \mathrm{~cm}$ and that of Group B was $166.1 \pm 8.4 \mathrm{~cm}$. The $p$ value calculated was 0.16 and was not statistically significant. In the study group $76 \%$ were males and $24 \%$ were females. Gender distribution among Group 1 and 2 were tested using chi square test and $\mathrm{p}$ value calculated as 0.19 which was found to be statistically insignificant. Distribution of ASA PS class 1 and 2 between Group A and B were tested using chi square test and $\mathrm{p}$ value calculated as 0.05 , which was statistically significant.

Sensory blocks were compared between the 2 groups. Onset of the sensory block was $9.04 \pm 1.74 \mathrm{~min}$ in Group A and $12.00 \pm 2.00 \mathrm{~min}$ in Group B. P value was $<0.001$ and the result was statistically significant. Duration of the sensory block was $589.20 \pm 56.60 \mathrm{~min}$ in Group A and $673.60 \pm 53.40$ min in Group B.

$P$ value $<0.001$ and the result was found to be statistically significant.

Onset of the motor block was $11.80 \pm 1.87 \mathrm{~min}$ in Group A and $15.48 \pm 2.08 \mathrm{~min}$ in Group B. P value was $<0.001$, and the result was statistically significant. Duration of the motor block was $502.8 \pm 60.9 \mathrm{~min}$ in Group A and $566.0 \pm 59.6 \mathrm{~min}$ in Group B. P value was $<0.001$ and the result was obtained as statistically significant.

Duration of analgesia was $665.2 \pm 52.2 \mathrm{~min}$ in Group A and $760.4 \pm 48.2 \mathrm{~min}$ in Group B. P value was $<0.001$ and the result was statistically significant.

Don Sebastian et al. conducted a study by comparing the effect of dexmedetomidine and clonidine as adjuvant to ropivacaine in supraclavicular brachial plexus nerve blocks. They have decided to compare two alpha-2 agonists clonidine and dexmedetomidine, when added as adjuvant to ropivacaine, in respect to onset, duration of sensory and motor block along with duration of analgesia. To ropivacaine $29 \mathrm{ml}$ (0.5\%), Group C received clonidine $1 \mathrm{ml}$ (50 $\mu \mathrm{g})$ and Group D received dexmedetomidine $1 \mathrm{ml}(50 \mu \mathrm{g})$. Onset of 
sensory and motor blockade was faster in Group D, which is statistically significant. The duration of sensory block and motor block, analgesia was also greatest in group $\mathrm{D}$, which is statistically significant. They found out that dexmedetomidine when added to ropivacaine in supraclavicular brachial plexus block had faster onset, greater duration of sensory and motor block and also, the duration of analgesia, than clonidine. Dexmedetomidine is better adjuvant than clonidine when added as adjuvant to ropivacaine in supraclavicular brachial plexus block. ${ }^{26}$

Anjan Das et al. studied about the effect of dexmedetomidine as adjuvant in ropivacaine-induced supraclavicular brachial plexus block: A prospective, doubleblinded and randomized controlled study.

A total of 84 patients (20-50 years) posted for elective forearm and hand surgery under supraclavicular brachial plexus block were divided into two equal groups (Group R and $\mathrm{RD}$ ) in a randomized, double-blind fashion. In group RD $(n=42) \quad 30 \quad \mathrm{ml} \quad 0.5 \%$ ropivacaine $+1 \quad \mathrm{ml} \quad(100 \mu \mathrm{g})$ of dexmedetomidine and group $\mathrm{R} \quad(n=42) \quad 30 \mathrm{ml} \quad 0.5 \%$ ropivacaine $+1 \mathrm{ml}$ normal saline was administered in the supraclavicular block. Sensory and motor block onset times and block durations were recorded for each patient. They found out that sensory and motor block duration and time to first analgesic use were significantly longer and the total need for rescue analgesics was lower in Group RD $(P<0.05)$ than Group R. Duration of post-operative analgesia was significantly longer in Group RD $(P<0.05)$. They concluded that adding dexmedetomidine to supraclavicular brachial plexus block increases the sensory and motor block duration. ${ }^{27}$

Suneet Kathuria et al. conducted a study regarding dexmedetomidine as an adjuvant to ropivacaine in supraclavicular brachial plexus block. 60 ASA grade I and II patients of either sex scheduled for elective upper limb surgery under supraclavicular brachial plexus block were divided into three equal groups in a prospective randomized double-blind controlled manner. For block patients in Group $\mathrm{C}$ received $0.5 \%$ ropivacaine $(30 \mathrm{cc}), 0.5 \%$ ropivacaine with $50 \mu \mathrm{g}$ dexmedetomidine (30cc) in Group D. Sensory block and motor block onset was earlier in Group D. The sensory block and motor block duration was also prolonged in Group D when compared with Group C. The duration of analgesia was significantly longer in Group D when compared to Group C. They concluded that dexmedetomidine as an adjuvant to $0.5 \%$ ropivacaine in brachial plexus block shortens the sensory as well as motor block onset time, prolongs sensory and motor block duration and also increases the duration of analgesia. 28

Indira Gurajala et al. studied the effect of perineural dexmedetomidine on the quality of supraclavicular brachial plexus block with $0.5 \%$ ropivacaine. 36 patients scheduled for orthopaedic surgery on the upper limb under supraclavicular block were divided into either R Group (35 ml of $0.5 \%$ ropivacaine with $0.5 \mathrm{ml}$ of normal saline) or RD Group $(35 \mathrm{~mL}$ of $0.5 \%$ ropivacaine with $50 \quad \mu \mathrm{g}$ dexmedetomidine. The onset time and duration of motor and sensory blockade were noted. The time of onset of sensory block was not significantly different. The proportion of patients who achieved complete motor blockade was more in the RD group. The onset of motor block was earlier in Group RD than Group $\mathrm{R}(P<0.05)$. The durations of analgesia, sensory and motor blockade were significantly prolonged in Group RD $(P<0.00)$. They concluded that the addition of dexmedetomidine to $0.5 \%$ ropivacaine improved the time of onset, quality, and duration of supraclavicular brachial plexus block. ${ }^{29}$

\section{CONCLUSIONS}

Comparing the effect of addition of clonidine versus dexmedetomidine as adjuvants to $0.5 \%$ ropivacaine in supraclavicular brachial plexus block for upper limb orthopaedic surgeries, based on onset and duration of sensory block, motor block and duration of analgesia. We conclude that addition of $1 \mathrm{mcg} / \mathrm{kg}$ of dexmedetomidine to $0.5 \%$ ropivacaine significantly prolongs the sensory block, motor block and duration of analgesia compared to $1 \mathrm{mcg} / \mathrm{kg}$ of clonidine. At the same time clonidine reduces the onset of sensory and motor block when added to $0.5 \%$ ropivacaine in supraclavicular brachial plexus block.

\section{REFERENCES}

[1] Cousins MJ, Bridenbaugh PO, Carr DB, et al. Neural blockade in clinical anaesthesia and pain medicine. $4^{\text {th }}$ edn. Lippincott Williams and Wilkins 2009.

[2] Morgan EG, Mikhail MS, Murray MJ. Peripheral nerve blocks. Chap- 17. In: Clinical anaesthesiology. $4^{\text {th }}$ edn. New Delhi: Tata McGraw Hill 2009.

[3] Russon K, Pickworth T, Harrop-Griffith W. Upper limb blocks. Anaesthesia 2010;65 Suppl 1:48-56.

[4] Kulenkampff D. Brachial plexus anaesthesia: its indications, technique, and dangers. Ann Surg 1928;87(6):883-91.

[5] McClellan KJ, Faulds D. Ropivacaine: an update of its use in regional anaesthesia. Drugs 2000;60(5):1065-93.

[6] Markham A, Faulds D. Ropivacaine. A review of its pharmacology and therapeutic use in regional anaesthesia. Drugs 1996;52(3):429-49.

[7] Simpson D, Curran MP, Oldfield V, et al. Ropivacaine: a review of its use in regional anaesthesia and acute pain management. Drugs 2005;65(18):2675-717.

[8] Pankaj K, Rajan PS. Alpha 2 agonists in regional anaesthesia practice: Efficient yet safe? Indian J Anaesth 2014;58(6):681-3.

[9] Casati A, Magistris L, Fanelli G, et al. Small-dose clonidine prolongs postoperative analgesia after sciatic-femoral nerve block with $0.75 \%$ ropivacaine for foot surgery. Anesth Analg 2000;91(2):388-92.

[10] Bernard JM, Macaire P. Dose-range effects of clonidine added to lidocaine for brachial plexus block. Anesthesiology 1997;87(2):277-84.

[11] Starke K, Altmann KP. Inhibition of adrenergic neurotransmission by clonidine: an action on prejunctional-receptors. Neuropharmacology 1973;12(4):339-47.

[12] Bousquet P, Guertzenstein PG. Localization of the central cardiovascular action of clonidine. $\mathrm{Br} \mathrm{J}$ Pharmacol 1973;49(4):573-9. 
[13] Nakamura M, Ferreira SH. Peripheral analgesic action of clonidine: mediation by release of endogenous enkephalin-like substances. Eur J Pharmacol 1988;146(2-3):223-8.

[14] Gerlach AT, Dasta JF. Dexmedetomidine: an updated review. Ann Pharmacother 2007;41(2):245-52.

[15] Bhana N, Goa KL, McClellan KJ. Dexmedetomidine. Drugs 2000;59(2):263-8.

[16] Hoy SM, Keating GM. Dexmedetomidine: a review of its use for sedation in mechanically ventilated patients in an intensive care setting and for procedural sedation. Drugs 2011;71(11):1481-501.

[17] Coursin DB, Coursin DB, Maccioli GA. Dexmedetomidine. Current Opinion in Critical Care 2001;7(4):221-6.

[18] Hadzic A. Supraclavicular Brachial Plexus Block. In: Hadzic's peripheral nerve blocks and anatomy for ultrasound guided regional anaesthesia. $2^{\text {nd }}$ edn. New York, USA: McGraw Hill 2012:167-174, 361-368.

[19] Vermeylen K, Engelen S, Sermeus L, et al. Supraclavicular brachial plexus blocks: review and current practice. Acta Anaesth 2012;63(1):15-21.

[20] Reiz S, Häggmark S, Johansson G, et al. Cardiotoxicity of ropivacaine--a new amide local anaesthetic agent. Acta Anaesthesiol Scand 1989;33(2):93-8.

[21] Hansen TG. Ropivacaine: a pharmacological review. Expert Rev Neurother 2004;4(5):781-91.

[22] Kuthiala G, Chaudhary G. Ropivacaine: a review of its pharmacology and clinical use. Indian J Anaesth 2011;55(2):104-10.
[23] Hirabayashi Y, Shimizu R, Fukuda H, et al. Effects of the pregnant uterus on the extradural venous plexus in the supine and lateral positions, as determined by magnetic resonance imaging. Br J Anaesth 1997;78(3):317-9.

[24] Morrison SG, Dominguez JJ, Frascarolo P, et al. A Comparison of the electrocardiographic cardiotoxic effects of racemic bupivacaine, levobupivacaine, and ropivacaine in anesthetized swine. Anesth Analg 2000;90(6):1308-14.

[25] Paris A, Tonner PH. Dexmedetomidine in anaesthesia. Curr Opin Anesthesiol 2005;18(4):412-8.

[26] Sebastian D, Ravi M, Dinesh K, et al. Comparison of dexmedetomidine and clonidine as adjuvant to ropivacaine in supraclavicular brachial plexus nerve blocks. IOSR J Dent Med Sci 2015;14:91-7.

[27] Das A, Majumdar S, Halder S, et al. Effect of dexmedetomidine as adjuvant in ropivacaine-induced supraclavicular brachial plexus block: a prospective, double-blinded and randomized controlled study. Saudi J Anaesth 2014;8(Suppl 1):S72-7.

[28] Kathuria S, Gupta S, Dhawan I. Dexmedetomidine as an adjuvant to ropivacaine in supraclavicular brachial plexus block. Saudi J Anaesth 2015;9(2):148-54.

[29] Gurajala I, Thipparampall AK, Durga P, et al. Effect of perineural dexmedetomidine on the quality of supraclavicular brachial plexus block with $0.5 \%$ ropivacaine and its interaction with general anaesthesia. Indian J Anaesth 2015;59(2):89-95. 